\title{
LA DESVIACION DE PODER EN LA ADMINISTRACION LOCAL $_{\dot{\Delta}}(1971-1978)$
}

35.072.22: 352

\author{
por \\ Jaime Sánchez Isac \\ Doctor en Derecho \\ Secretario de primera categoría de Administración Local
}

SUMARIO: I. INTRODUCCION: OBJETO DE ESTE ESTUDIO.II. ESTUDIO DE LOS CASOS ACEPTATORIOS DE LA DESVIACION DE PODER: 1. LA DESVIACIÓN DE PODER Y LOS RESTANTES VICIOS DEL ACTO ADMINISTRATIVO. 2. LA DESVIACIÓN DE PODER Y LAS CUESTIONES DE PERSONAL. 3. DESVIACIÓN DE PODER Y URBANISMO. DEFENSA DEL PATRIMONIO MUNICIPAL Y OTROS SUPUESTOS CONEXOS.III. EVOLUCION DEL CONCEPTO DE DESVIACION DE PODER: LABOR JURISPRUDENCIAL SOBRE ASPECTOS DOCTRINALES DE LA MISMA: 1. DEFINICIÓN Y CLASES DE DESVIACIÓN DE PODER. El PROBLEMA DEL INTERÉS GENERAL. 2. LA PRUEBA Y LA DESVIACIÓN DE PODER. 3. UN SUPUESTO DE APELACIÓN ADMITIDA CONTRA SENTENCIA ACEPTATORIA DE DESVIACIÓN DE PODER. INVALIDEZ «VERSUS» CERTEZA DEL ACTO ADMINISTRATIVO. - IV. CONCLUSIONES.

\section{INTRODUCCION: OBJETO DE ESTE ESTUDIO}

Nos hemos planteado la conveniencia de una investigación jurisprudencial muy concreta: la evolución de la desviación de poder en la Administración local, desde 1971 a 1978. 
Nuestra atención por el tema (1), en extensión y profundidad: casuística, ya hace algunos años, nos ha movido a continuar el estudio, hasta la actualidad, centrándolo en la Administración local.

El trabajo de delimitación doctrinal del tema, que se ha llevado. a cabo por la doctrina, en estos últimos años (2), nos permite, por otra parte, obviar el aparato bibliográfico y las referencias científicas, para centrarnos singularmente en unas sencillas consideraciones sobre la labor del Tribunal Supremo, tomando, como pie forzado de las mismas, el control verificado sobre la Administración local, aparte de algunas matizaciones marginales sobre la evolución del tema en el Derecho francés, siguiendo el paralelismo del estudio que nos ocupó en su día.

Parece que este campo de la Administración local es especialmente proclive a la alegación de la desviación de poder, que ha sido uno de los más socorridos motivos de impugnación, por su propia generalidad y potencia expansiva.

Existen, además, factores psicológicos que deben tenerse en cuenta. En la Administración local, singularmente en los Ayuntamientos, los órganos decisores viven en proximidad física con los administrados. Su carácter político, aun contando con los mecanismos correctores del funcionariado, hace que, en muchos casos, la racionalidad administrativa se vea matizada por actitudes y aptitudes personales que se integran, de mejor o peor forma, en el quehacer de la Administración.

No queremos decir con ello que la Administración local sea más arbitraria que las otras Administraciones. Al contrario. Posiblemente su carácter doméstico y popular, en gran número de supuestos, le permite un mejor conocimiento de los problemas y de sus soluciones. Intentamos explicitarnos por qué la desviación de poder es uno de los títulos más socorridos en la justicia administrativa de la Administración local-tal vez en un mismo plano de frecuencia que en los otros campos de la Administración-, a la vista de los Repertorios de Jurisprudencia, para llegar a la conclusión plausible de que la atipicidad, la inmediatez de las relaciones personales, la espontaneidad y la vitalidad, notas características

(1) JaIme Sánchez Isac: La desviación de poder en los Derechos francés, italiano y español, I. E. A. L., Madrid, 1973.

(2) M. Alvarez Rico y V. M. González-Haba Guisado: «La desviación de poder en materia de personal», Documentación Administrativa, enero-febrero 1974, núm. 157, páginas 25-65. 
del medio social en que actúa, pueden ser factores concurrentes para la aparición del fenómeno.

Por otra parte, la coyuntura española de la democratización y del informalismo administrativo en que vivimos hace que la desviación de poder sea, sin duda, una de las expresiones que veremos más repetidas en nuestra función profesional, que nos confiere una óptica ad intra de los fenómenos administrativos.

\section{ESTUDIO DE LOS CASOS ACEPTATORIOS DE LA DESVIACION DE PODER}

Una primera visión panorámica del tema nos permite comprobar, en el lapso de tiempo observado, algo que ocho años antes no era evidente: la desviación de poder tiene una discreta vitalidad en nuestro sistema contencioso-administrativo. Ciertamente, la gran mayoría de casos estudiados nos arrojan un claro predominio de la denegación (3), pero lo cierto es que la figura no se halla en proceso de extinción, sino todo lo contrario.

\section{LA DESVIACIÓN DE PODER Y LOS RESTANTES VICIOS DEL ACTO ADMINISTRATIVO}

Existe una clara tendencia a separar la desviación de poder de las restantes formas de infracción del ordenamiento jurídico. Así, en la Sentencia de 19 enero 1971 (4) se diferencia de la incompetencia por razón de la materia, indicándose que la «vulneración legal producida, que por su complejidad desborda la expresión típica estricta de desviación de poder y llega a la mayor infracción del ordenamiento legal que enmarca la esfera de acción municipal, excluyendo de ella relaciones de naturaleza extra-administrativas».

Con ello se tiende a definir y matizar la desviación de poder en su especificidad teleológica que ha determinado, asimismo, la doctrina de su incompatibilidad con cualquier otro defecto de nulidad,

(3) De los 59 casos estudiados, sólo 14 son aceptatorios. Recordemos que M. AlvaREZ Rico y V. M." GonzÁlez-Haba hallaron dos casos de aceptación en 50 casos estudiados.

(4) Sala 4." R. 164. Se requirí por el Gobierno Civil a un Ayuntamiento que fasilitara suministro de agua potable a una vivienda. La Corporación municipal trasladó a una Sociedad Anónima el cumplimiento de tal obligación. 
absoluta o relativa, lo que conlleva la falta de base para su apreciación (5) en los actos dictados en cumplimiento de una norma, dado su carácter subsidiario.

\section{LA DESVIACIÓN DE PODER Y LAS CUESTIONES DE PERSONAL}

Es clara la aceptación de supuestos en aquellas modificaciones de plantillas tendentes a evitar el reintegro al servicio activo de funcionarios excedentes voluntarios.

Es un fenómeno bien conocido la complejidad y premiosidad de los expedientes disciplinarios, aparte de su carácter odioso. La tentación de la «sanción indirecta» es muy viva, en muchos casos, como una solución subrepticia de una cuestión concreta. Ciertamente, el llamado "poder organizatorio", como ámbito de discrecionalidad determinada, con sus consecuencias inmediatas en los medios personales, los funcionarios, debe sujetarse al principio general de todas las competencias: el interés general.

(5) En torno a esta cuestión caben destacar las siguientes Sentencias: 3 febrero 1971 (R. 394): "no cabe en la aplicación estricta de la Ley de Aguas, Reglamento de Policía de Aguas y concordantes»; 15 noviembre 1971 (R. 4534): "si el Ayuntamiento de... cumplió con una obligación legal, cual es la derivada del artículo 511 de la Ley de Régimen local, mal puede hablarse de desviación de poder por la expresada Entidad»; 6 noviembre 1973 (R. 4326): «desde el instante en que por los recurrentes se acusan pretendidas infracciones de textos legales como pasa aquí..., es obvio que no puede ser aplicable la mencionada teoría de la desviación de poder»; 28 marzo 1973 (R. 1313): «es una de las formas de infracción del Ordenamiento jurídico, configurado por la Ley de 27 de diciembre de 1956 como un supuesto concreto de ilegalidad del acto administrativo, que en el ejercicio de su potestad discrecional se emplea para fines distintos de los fijados por él, lo que no cabe concebir como cualquier clase de violación de las normas, pues de entenderse de este modo toda vulneración de una ley o antecedente, en última instancia, sería una desviación de poder...»; 31 enero 1976 (R. 744): «... al haber vulnerado el acto recurrido la legislación vigente, está fuera de lugar entrar a conocer de la posible existencia de la "desviación de poder alegada"...»; 25 octubre 1976 (R. 5574): «es por ello procedente la estimación del re. curso al no ser conforme a Derecho los acuerdos recurridos sin que sea preciso entrar en el examen de la alegada desviación de poder en la actuación administrativa, pues como enseña la jurisprudencia, estimando que la Administración no se atemperó a la legalidad externa que debe presidir su actuación, resulta superfluo adentrarse en la supuesta discordancia entre los motivos que guían la actividad administrativa y los fijados por el Ordenamiento jurídico»; 26 abril 1977 (R. 2649): "de donde se infiere en primer lugar la evidente incompatibilidad entre pretensiones de anulación del acto administrativo con fundamento en su mera ilegalidad y a la vez basadas en desviación de poder, siendo tan sólo dable ese dualismo cuando se presentan en forma de pretensiones alternativas; pero aun así necesario será que la desestimación de la principal no conlleve aceptación de situaciones que hagan imposible el planteamiento de otras amparadas en la desviación de poder». 
En este sentido, las Sentencias de 12 abril 1973 (6) y 6 mayo 1975 (7).

En ambas queda muy claro que lo que no puede hacer la Administración es imponer una «sanción encubierta» bajo las apariencias de unos patrones ideales de "reducir el costo de los servicios» o «reordenar los servicios en aras de la mayor eficacia de su prestación».

En ambas Sentencias se acude, ante supuestos de mínima entidad administrativa-supresiones de una plaza de auxiliar administrativo y de subalterno, respectivamente-a la doctrina de la desviación de poder, que permite enjuiciar a fondo la potestad discrecional, propia de la materia organizatoria, bajo criterios de la más absoluta tipicidad y rotundidad expresivas.

Existen paralelismos remarcables en la jurisprudencia del Consejo de Estado francés, como el arrêt de 23 marzo 1979, «Le Gall», donde se prescribe la supresión de la plaza de responsable de un matadero municipal, para crear la de regente con posterioridad, de las mismas funciones, y con tal motivo revocar el nombramiento del interesado que desempeñaba la primera; todo ello con ánimo sancionatorio (8).

(6) Sala $5 .^{\mathrm{a}} \mathrm{R}$. 1535 . Se recurre a «pruebas indirectas, cuya valoración conjunta permita deducir la existencia bajo la apariencia de legalidad de una finalidad ilícita». La Sala llega «a la firme convicción de que el móvil fundamentalmente inspirador de los acuerdos recurridos ha sido el de tratar de impedir con carácter definitivo el previsto reingreso del funcionario a causa de esa supuesta conducta irregular, conducta que, de ser cierta, tiene en la vía penal o disciplinaria la sanción legalmente establecida».

Alvarez Rico y González-Haba (art. cit., pág. 43) explicitan el fenómeno en los siguientes términos: «Muchas veces la Administración, cuando se encuentra con la limitación de las normas que se refieren, por ejemplo, a cuestiones como retribuciones, traslados, nombramientos, etc., corre el riesgo de utilizar sus facultades para sortear el mandato de las normas respectivas y conseguir de forma ilegal lo que no ha podido conseguir por una actuación con arreglo a Derecho».

(7) «La prueba de la existencia del expediente disciplinario... confirma cómo con posterioridad a la ocurrencia de suprimir para el futuro la plaza, cargo, destino o puesto de trabajo del demandante, para sancionarle bajo el disfraz de un traslado a otro, supuestamente semejante o análogo, se había intentado hacerlo, imponiéndoselo de modo arbitrario y corriendo en vía disciplinaria...»

(8) C. E. 23 marzo 1979, «Le Gall», R. D. P., 1979, pág. 1503: «Considerando que se evidencia en los documentos del expediente que por deliberación de 19 de julio de 1974 el Consejo Municipal de Lourdes decidió suprimir el empleo de responsable administrativo del matadero municipal que ocupaba M. Le Gall; que, asimismo, se evidencia en el extracto del libro de las deliberaciones del Consejo que los verdaderos motivos de esta decisión se referían al comportamiento profesional que se le reprochaba al interesado; que, en consecuencia, después de haber suprimido este empleo, el Consejo Municipal procedió a la creación de la plaza de regente del matadero, conllevando las mismas funciones, y que, por tanto, el acuerdo de 19 de julio de 1974, así como el acto del mismo día de la Alcaldía de Lourdes, adoptado para po- 
En otras Sentencias, de 7 octubre 1971 (9) y 2 abril 1978 (10), se tiende a proscribir la predeterminación de los concursos, convocados para proveer plazas de funcionarios. Ambos supuestos se refieren a un mismo caso, en el que los méritos a apreciar por el Tribunal eran «las garantías de moralidad, solvencia, honorabilidad, prudencia, energía de los solicitantes», entre otros. Destaca asimismo la visión conjunta del desarrollo del procedimiento, para llegar a la conclusión de que se "configura la desviación de poder, ya que, encubriéndolo bajo el aspecto de legalidad externa de un concurso, se cumplió el designio preconcebido de conferir el nombramiento de... a D...».

En estas Sentencias, por tanto, se tiende a depurar la acción administrativa de cualquier adherencia favoritista o discriminatoria. Ello es altamente beneficioso en un campo como el funcionarial, donde las posibilidades de tales fenómenos son tristemente posibles y relativamente frecuentes.

\section{Desviación DE Poder y URbanismo. DefENSA del Patrimonio MUNICIPAL Y OTROS SUPUESTOS CONEXOS}

El ejercicio de la actividad reglada de concesión de las licencias para edificaciones y establecimientos industriales concede a los Ayuntamientos unos poderes de control del ius aedificandi y de la actividad mercantil e industrial de los particulares que puede ser base de actuaciones tendentes a la defensa del patrimonio municipal, en cuanto pueda resultar afectado por actos jurídicos de los ciudadanos. El carácter vituperable o disfuncional que puede ostentar la desviación de poder parece, en este caso, paliado por la finalidad espúrea, que ciertamente no es ilegal en sí sino en cuanto al procedimiento seguido.

Entre los recientes supuestos podemos citar la Sentencia de 29 mayo 1971 (11), donde se insiste en aspectos fundamentales de

ner fin a las funciones de M. Le Gall, para asegurar la ejecución ha tenido por objeto pronunciar, de forma desviada, la revocación de $M$. Le Gall; que por ello $M$. Le Gall ha sostenido fundadamente que el Tribunal Administrativo de Pau ha rechazado con error su demanda, tendente a la anulación del acto de 19 de julio de 1974, mediante el cual el Alcalde de Lourdes puso fin a sus funciones».

(9) Sala 5.' R. 3873.

(10) Sala 5.. R. 1498.

(11) Sala 4." R. 2950. Se concedió licencia para ampliación de locales comerciales en unos bajos que, posteriormente, fue anulado en cuanto las obras necesarias ocupaban parte de la vía pública. 
una doctrina constante y que puede considerarse como tradicional, sobre aspectos muy concretos, entre los que destacan:

a) La constancia de que el fin del acto, «aunque inspirado en la consecución de un beneficio para la cosa pública, sobre el uso de la acera controvertida, no encaja exactamente el procedimiento para ello seguido por el Ayuntamiento de..., dentro de la finalidad ínsita de los poderes que se utilizaron por la Administración municipal, a tal efecto».

b) La necesidad de que se respete por la Administración la propiedad privada, amparada por las leyes institucionales civiles, singularmente la Ley Hipotecaria que estatuye-art. 198-la concordancia entre el Registro y la realidad extrarregistral, frente a la que no pueden prevalecer las normas de la legislación administrativa sobre recuperación de oficio de los bienes de dominio público, dictadas para otros supuestos y que son el expediente más socorrido en esta línea de las desviaciones de poder, evidentemente la más numerosa.

c) La ilegalidad existente en la utilización de las potestades municipales de revocación de licencias municipales con la finalidad de ganar tiempo para tramitar un plan de ordenación, supuesto que, obviamente, puede comprender cualquier fórmula de reordenación urbanística que se quiere obtener con la revocación en cuestión (12).

En el mismo sentido se veta en la Sentencia de 27 febrero 1976 el uso de las potestades de suspensión de licencias de obras presuntamente ilegales con la finalidad de recuperar un solar al que creía tener derecho (13) una Corporación municipal. En sentido

(12) «En nuestro caso presente no consta que haya tales planes que afecten al terreno al que la licencia se refiere, pero a través de este desfasado recurso se puede ganar evidentemente un tiempo que de otra manera estaría irremisiblemente perdido para las apetencias urbanísticas del Ayuntamiento, y en tal sentido aunque éste sirva inmediatamente a la causa pública, lo hace fuera de los fines para los que el otorgamiento de la licencia fue concedido y fuera de las típicas causas de revocación de ella de que se vale para enervar la eficacia dimanante de la postura del particular acogido al estado de Derecho derivada de la legalidad de la primera licencia otorgada al mismo por el Ayuntamiento...»

(13) Sala 4." R. 1481. Quinto Considerando de la Sentencia apelada: «... resulta claro que el Ayuntamiento no ha utilizado las facultades que le concede el artículo 171 de la Ley del Suelo, único que autoriza la paralización de las obras con la teleológica de. terminación a que el precepto responde, pues si bien entre las condiciones de la licencia figura el plazo de ejecución, no fue el vencimiento de éste, de cumplimiento imposible atendidas las circunstancias concurrentes, el que decidió la suspension por 
contrario, esto es, admitiendo la licitud de suspensión de una licencia, con el expreso y claro motivo de reivindicar un terreno de dominio público, indebidamente ocupado, hallamos la Sentencia de 12 marzo 1973 (Sala 4. ${ }^{\text {a }}$ R. 1141).

Igualmente se considera en Sentencia de 3 julio 1973 incurso en desviación de poder el procedimiento seguido por un Ayuntamiento para obtener terrenos destinados a construcción de escuela, consistente en tramitación de un expediente de clasificación de vías pecuarias y posterior deslinde, del que había de resultar un sobrante, de propiedad municipal (14).

En conjunto, puede afirmarse que el Tribunal Supremo ha delimitado muy claramente la necesidad del respeto a la propiedad privada en materia urbanística, y que los rasgos institucionales que la caracterizan en nuestro ordenamiento no pueden ser desviados o deformados mediante un uso excesivo de las potestades administrativas, en el campo de las licencias, singularmente con la finalidad de proteger o acrecentar el patrimonio municipal mediante vías inadecuadas.

Incluso sin existir beneficio económico se llega a la aceptación de tal desviación de poder en la Sentencia de 23 febrero 1972 (15),

la invocada caducidad, sino que se utilizó aquella potestad para invalidar la licencia, favoreciendo el estudio de los derechos que pudiera hacer valer el Ayuntamiento para la recuperación de parte del solar a la que creía tener derecho y sobre cuya improcedencia en casos similares se ha pronunciado reiteradamente la jurisprudencia-Sentencias de la Sala 4." del 27 marzo 1961 (R. 1533), 10 diciembre 1963 (R. 5286), 18 enero 1964 (R. 147), 27 enero 1970 (R. 230), 2 marzo 1972...-, por lo que ha de entenderse se incidió en el supuesto del artículo 82, 2 y 3, de la L. J.»

(14) R. 3302. Sala 4.: «... en el expediente hay constancia evidente de que la Administración ordenó su incoación exclusivamente en virtud de las razones que el Ayuntamiento expuso; esto es, para facilitarle mediante el ulterior mecanismo de adquisición preferente del terreno declarado sobrante la construcción de escuelas y viviendas para los maestros. Esta constancia es tan significativa y manifiesta que constituye uno de los considerandos (el segundo) o fundamentos jurídicos de la Resolución ministerial impugnada, que textualmente dice: "que el deslinde al que se concreta el recurso fue ordenado por la Dirección General de Ganadería a instancia del Ayuntamiento de..., al objeto de hacer posible con ello la posterior enajenación de parte de los terrenos al citado Ayuntamiento para construir en los mismos con carácter de urgencia un grupo escolar con viviendas para maestros"».

(15) Sala 4." R. 646: «... tras examinar la abundante prueba y el resultado de su reconocimiento judicial in situ de las fuentes, lugares y finca implicadas, expone en su primero a cuarto considerando las conclusiones siguientes: primera, que no sólo resulta improbado que los hechos contemplados por el Municipio como causa de su decisión... provengan de deficiencias de la fuente allí instalada, sino que aparecen rotundamente contradichos y negados por la evidencia...; segunda, que tampoco puede justificarse el acuerdo en la necesidad o siquiera conveniencia para el interés público de que en la Avda. del Puente, y precisamente en el lugar en que se sitúa, se instalara una fuente y abrevadero, ya que a 42 pasos-unos $30 \mathrm{~m}$.- -hay otra en funcionamiento...; tercera, que a través de ese "control de los hechos» contemplados por la Administración con el carácter de causa de su decisión, se llega al convencimiento de 
donde hallamos un claro supuesto de control de los hechos ante unas obras municipales consistentes en construcción de un abrevadero para ganado, con obstrucción de una puerta en propiedad privada. Existe, en la concreta cuestión, una voluntad finalista de la Administración ajena al interés público, hallándonos, por tanto, ante una clara y flagrante desviación.

\section{EVOLUCION DEL CONCEPTO DE DESVIACION DE PODER: LABOR JURISPRUDENCIAL SOBRE ASPECTOS DOCTRINALES DE LA MISMA}

\section{Definición y Clases de desviación de Poder. El PROBlema DEL INTERÉS GENERAL}

Creemos justo subrayar una Sentencia especialmente rica en afirmaciones doctrinales, la de 4 abril 1972, desde el ángulo concreto del Derecho local.

La Sentencia apelada se replantea la definición de desviación de poder (16) y su clasificación en orden a la importancia del fin espúreo (17), como ha hecho notar el Profesor Santamaría PasTOR (18).

la inexistencia de tal elemento constitutivo del acto administrativo impugnado, y que enseña asimismo la ausencia de interés público inexcusable para legitimar el ejercicio de la función administrativa, mostrándose la desviación del fin propio de la actuación municipal combatida».

(16) Sala 4." R. 2204. Se trata de un típico caso de discriminación de la libertad de comercio. Un labrador, usuario del Mercado Central de Entradores de Sevilla, utilizaba a los descargadores que allí existían. Posteriormente decidí llevar operarios propios, lo cual le fue prohibido por las autoridades del Mercado. El Ayuntamiento confirmó lo actuado. La Audiencia Territorial aceptó la desviación de poder, con confirmación del Tribunal Supremo.

(17) Tercer Considerando de la Sentencia apelada: «si la Administración utiliza sus potestades para conseguir un fin que no sean aquéllos, comete desviación de poder sustancial, que puede así caracterizarse como una "malversación" de sus potestades, y puede ser absoluta si se persiguen fines extraños al interés público, o relativa, si se persigue un fin que, aunque público, no es el específicamente asignado para el acto de que se trata, y puede finalmente aparecer como desviación de procedimiento si con el objeto de conseguir una determinada finalidad pública se utiliza un procedimiento que no es el específicamente previsto por la Ley, lo cual aparece en ocasiones como un instrumento al servicio de desviaciones sustanciales.

(18) Esta Sentencia ha sido comentada en términos altamente elogiosos por el Profesor J. A. SANTAMARÍa PASTOR en el comentario monográfico «Renovación dogmática en torno a la desviación de poder como instrumento de control (CIVITAS, Revista Española de Derecho Administrativo, núm. 2, pág. 307), haciendo constar, desde una optica general, su valor ejemplar, en cuanto a la esencia de la desviación de poder, por diferenciarse la desviación de poder sustancial y la relativa, así como la recepción de la desviación de procedimiento en la jurisprudencia española. 
La Sentencia se remonta a los orígenes de la figura, en la doctrina del Consejo de Estado francés, en unas consideraciones doctrinales de tipo general, realmente insólitas en nuestra práctica jurisprudencial, para entrar en el fondo de la cuestión y afirmar la discriminación efectuada por la Administración municipal en relación a una Cooperativa de descarga del Mercado Central, con un privilegio o trato favorable que no tiene su base ni en una situación jurídica contractual «derivada de concesión, arrendamiento o concierto, como medios de gestión indirecta de servicios municipales", esbozando un abanico de las formas contractuales típicas del Reglamento de Servicios.

Al actuarse en el sentido de prohibir al recurrente la carga y descarga de mercancías con su propio personal, se da la desviación de procedimiento-calificándose así-, ya que de todo ello «se deriva inmediatamente la indirecta consagración de una situación preferente de la Cooperativa», llegándose a la consecuencia final de que «es difícil justificar que el interés que la Cooperativa representa no sea exclusivamente privado".

Es interesante constatar cómo en esta resolución se maneja, sin duda ni timidez, el concepto de interés público como elemento decisorio a la hora de aquilatar la corrección de la actuación administrativa, entroncando la desviación de poder con el fundamento básico de su actuación, justificador de la reacción anulatoria de la Sentencia.

En su análisis llega a una triple desviación de poder, al aplicar su esquema a la especie concreta que controla:

- «La utilización de la técnica de las utilizaciones singulares a terceras personas para consagrar una exclusiva en favor de la Cooperativa sin abordar directamente la solución de ésta»: desviación de procedimiento.

- «En cuanto tales prohibiciones singulares constriñen a los terceros a la obligatoria utilización de los servicios prestados por otra, suponen otra desviación de procedimiento".

- «Representando la entidad favorecida un interés privado, aquellas desviaciones de procedimiento aparecen como una desviación de poder sustancial y absoluta».

En definitiva, como la propia Sentencia indica, toda desviación de procedimiento debe reconducirnos a una desviación absoluta o relativa. 
El valor que pretende salvaguardar es la prohibición de discriminaciones, capital en cualquier actividad de Policía local, principio tradicional en la desviación de poder, tanto en nuestro Derecho como en el Derecho francés, como hace notar Marcel WALINE (19), comentando el arrêt C. E. 14 mars 1979, «Auclair».

Es claro que en la Sentencia de 4 de abril 1972 y en el arrêt de 14 marzo 1979, «Auclair» (20), se maneja el mismo principio capital del interés público, concreta y minuciosamente citado, en nuestra jurisprudencia, en una larga serie de Sentencias (21) e implíci-

(19) «Les pouvoirs de police municipale sur les ventes en ambulance. Etendue du contrôle juridictionnel», R. D. P., 1979, pág. 1163 .

(20) MARCEL WALINE (art. cit.) comenta la materia en los siguientes términos: "La policía municipal se ha interesado siempre en el comercio ambulante, y tal vez con preocupaciones extrañas al interés público; más exactamente, la autoridad municipal ha adoptado frecuentemente, en el pasado, medidas discriminatorias inspiradas en la intención de favorecer a los comerciantes fijos que pagan licencia y... son electores en el Municipio, circunstancia que no siempre deja de influenciar a los elegidos». En el caso comentado-C. E. (sect.), 14 mars 1979, «Auclair»-el Alcalde de Ramatuelle prohibió la venta ambulante y el estacionamiento de vehículos, dedicados a tal venta, en las playas del Municipio y en las inmediaciones de la playa de Pampelonne durante la temporada de baños. En el texto del arrêt se dice: «El Alcalde de Ramatuelle, que tenía en el artículo 97 del Código de Administración Municipal el poder de prevenir las perturbaciones al orden, la tranquilidad y salubridad públicas sobre el total territorio municipal y, en particular, en el dominio público marítimo, ha podido legalmente, en las circunstancias del caso, restringir en las playas de la Municipalidad el ejercicio de la libertad de comercio y de industria mediante el acto impugnado; por el contrario, los inconvenientes que presenta la venta y el régimen de ambulancia en los alrededores de la playa de Pampelonne no ostentaba un carácter de gravedad suficiente como para justificar en tales lugares una interdicción general...». WALINE comenta: «... el Consejo se preocupa de precisar que la interdicción de la venta en ambulancia no es legal tan sólo en las playas y espacios inmediatos, es decir, en los lugares precisos en donde los peligros, destacados, son más virulentos. Por el contrario, estos inconvenientes no tienen la misma gravedad en el resto del término municipal. Así, la Resolución municipal sólo es legal en la medida en que se refiere a las playas y espacios inmediatos. Se anula en lo que concierne al resto del término. Encontramos aquí el cuidado constante del Juez administrativo en limitar siempre cuidadosamente el ámbito de las prohibiciones de policía a los exclusivos lugares en los que las necesidades de orden, seguridad, salubridad y tranquilidad públicas los justifican».

(21) Sentencia de 28 marzo 1973. R. 1313: "tal alegación confunde la discrecionalidad administrativa para apreciar el interés público y la oportunidad de una determinada decisión..., con la interpretación que de las normas reguladoras de una materia, antes de emitir sus actos, ha de llevar a cabo la Administración...». Sentencia de 12 marzo 1971. Sala 4." R. 2177: "la desviación de poder, como vicio del acto, podría aducirse si la Administración autora de aquél se hubiera apartado de la teleológica significación del Registro, movida no por el fomento renovador de la ciudad, sino por otro fin, extraño al concreto público en que se asienta aquel instituto, mas es patente que si la situación de los inmuebles es de las definidas en el artículo $5 .^{\circ}$ del Reglamento de 5 de marzo de 1964 y no concurre causa obstativa a la inclusión, la inscripción, aunque a la par favorezca al privado interés del propietario, da satisfacción a un interés público...». Sentencia de 22 enero 1972. Sala 4. ${ }^{a}$ R. 233: "habiéndose justificado plenamente que la casa que ocupaban los actores se hallaba en estado de inminente peligro de derrumbamiento, era el Alcalde no sólo el llamado, sino el obligado a ordenar su desalojo... En consecuencia, el fin del acto administrativo que 
tamente presente en muchas otras, donde se puede plantear la concreción casuística que nuestro Tribunal Supremo ha dado al principio jurídico indeterminado esencial de la actividad administrativa (22).

ahora se recurre no fue desvirtuado, sino que fue dictado contemplando el interés público, norte insoslayable de todo buen hacer de la Administración...». Sentencia de 2 mayo 1972. Sala 5. ${ }^{\mathrm{a}}$ R. 2167: "los argumentos expuestos por el apelante... sobre el modo como debía el Tribunal calificador valorar los méritos de los candidatos... no son materia que pueda ser sometida a la consideración de la Sala, puesto que ese extremo no se refiere a ningún acto administrativo discrecional, donde al apreciar el interés público concreto del caso fuese posible que la Administración incidiese en desviación de poder...». Sentencia de 11 diciembre 1972. Sala 4. ${ }^{\mathrm{a}}$ R. 5269: «la expropiación fue motivada $a$ un interés público como es la urbanización de una calle de la villa». Sentencia de 31 marzo 1975. Sala 4." R. 2385: "por cuanto... se ha tratado de cumplimentar la finalidad genéricamente prevista en el Ordenamiento, utilizando la libertad de acción que éste le atribuye y ponderando la oportunidad; en efecto, el interés público ínsito en los sistemas de contratación está representado por el logro de la máxima calidad y economía...; en definitiva, un mayor beneficio enraizado en el mismo objeto del contrato, con el designio de la mejor satisfacción de las necesidades públicas». Sentencia de 26 abril 1977. Sala 4." R. 2684: "a tenor de la significación correspondiente al mismo en el artículo 83,2 , de la L. J., dicho concepto tiene por referencia una discordancia entre la motivación interna del acto administrativo impugnado y el interés público a que sirve la norma que circunstancialmente concreta a dicho interés...».

(22) Entre las Sentencias con una clara referencia implícita al interés público podemos citar las siguientes: Sentencia de 22 de diciembre 1972. Sala 3. R. 5314: No existe desviación de poder en la aprobación de un arbitrio con fin no fiscal sobre construcciones abusivas, ya que «se ha buscado en la Ordenanza combatida... la coerción sobre los transgresores de la ordenación urbanística que les obligará a realizar una determinada actuación». Sentencia de 7 octubre 1972. Sala 5." R. 3948: «la instalación del colector en terreno municipal y no privado supone un beneficio a la colectividad». Sentencia de 3 febrero 1976. Sala 4." R. 681/77: "la modificación pretendida por los recurrentes en orden al régimen instituido en la Ordenanza 15-A no se ha denegado inmotivadamente o acudiendo a tergiversaciones o errores fácticos, sino sobre la base razonada de que si bien es atendible una modificación, no lo es en los términos pretendidos por implicar un incremento excesivo de volumen edificable, creador de situaciones de densificación congestiva, lo que, en modo alguno, implica el ejercicio espúreo o tergiversado de competencias urbanísticas». Sentencia de 4 febrero 1977. Sala 4. ${ }^{a}$ R. 539. Recurso interpuesto contra la resolución del Ministerio de Gobernación sobre municipalización de un servicio de abastecimiento de agua potable de un Municipio: «esta desviación, que, por otra parte, no se advierte en el tema debatido, ya que-por el contrario-se acusa el deseo de mejorar un servicio público muy necesitado de perfeccionarse». Sentencia de 3 mayo 1978. Sala 5." R. 1668: «siendo el fin de la exigencia de condiciones en los concursos el que el elegido reúna los mejores requisitos de competencia y aptitud..., no aparece que la finalidad perseguida por la Diputación... sea contraria a los fines normales, sino antes al contrario, el pretender que el designado reúna las mayores garantías de competencia para el desempeño de la función que le va a ser encomendada...».

Sobre el concepto de interés es importante el estudio del Profesor don Fernando SAIZ MORENo Conceptos jurídicos, interpretación y discrecionalidad administrativa. En este libro (pág. 327) se insiste en un aspecto que tiene especial vinculación con la desviación de poder: el interés público, núcleo de las decisiones administrativas discrecionales. Esta postura está de acuerdo con la Exposición de Motivos de la Ley Jurisdiccional, donde (IV, 3) se define la discrecionalidad como la delegación, en la Administración, por el Ordenamiento jurídico, de «la configuración según el interés público del elemento del acto de que se trata». Ello explica-en el emparejamiento habitual 
En la moderna doctrina francesa se ha estudiado por DIDIER TRICHET (23) esta íntima trabazón entre desviación de poder e interés general, para llegar a la conclusión de la existencia de una nueva técnica del Consejo de Estado: la verificación, en el contencioso de nulidad, de la justificación del acto administrativo, en el interés general, que ha de existir en su base (24).

\section{LA PRUEBA Y LA DESVIACIÓN DE PODER}

La proclividad de los recurrentes a imputar a la Administración el grave vicio de la desviación ha sido equilibrado por la exigencia de una prueba contundente y convincente, por la interacción de la presunción de legitimidad o legalidad del acto administrativo. Esta exigencia de prueba es una constante jurisprudencial (25), correlativa a la corriente dominante, que ha sido la negativa.

de desviación de poder y discrecionalidad-que en tan gran número de Sentencias, resolviendo en la materia, se utilice la expresión interés público de modo específico, como hemos visto.

(23) DIDIER TRICHET: Les fonctions de la notion d'intéret général dans la jurisprudence du Conseil d'Etat, Bibliothèque de Droit Public, París, 1977. Este autor efectúa lo que él llama "ensayo de nueva presentación» de la doctrina de la desviación de poder. En definitiva, consiste en negar el «tipo 2 »-en su terminología-de desviación de poder, que coincide con la relativa de la Sentencia de 4 abril 1972, a la que nos hemos referido, en base de la escasez del número de los supuestos en que se admite su ambigüedad y la creciente dificultad de aceptación de la desviación en materia económica. En consecuencia, propone la supresión en la jurisprudencia de aquellas desviaciones que tienden a fines públicos, distintos de los específicamente determinados, según el propio ordenamiento habilitante del acto, ante la aparición de una técnica ampliamente estudiada (págs. 112 y ss.): la exigencia de que un acto esté justificado por el interés público.

(24) El interés general, según este autor, actúa en una doble función:

- Como factor negativo: En cuanto se exige, en todo caso, que la actuación ad. ministrativa se base en el interés general.

- Como factor positivo: El interés general viene a ser una condición del acto administrativo. Ha de existir una relación de conformidad entre el interés y los motivos del acto administrativo.

(25) Cabe destacar las siguientes Sentencias:

Sentencia de 5 junio 1971. Sala 4." R. 3623: "del examen de todo el expediente y de todos los antecedentes aportados aparece que el señor... ha tenido una serie de facilidades por parte de la Corporación Municipal de $M$. que rozan aspectos muy discutibles de legalidad; ... no puede desprenderse el que la actuación legal actual constituya una desviación de poder, máxime cuando, como se ha indicado, ni se ha acreditado su existencia y ni aun siquiera alegado hechos con actos que la puedan configurar...". Sentencia de 24 febrero 1971. Sala 5." R. 848: "... no ser posible reconocer que haya aportado ni siquiera enunciado de modo fundamentado actuación que conduzca a atribuir al Organo administrativo....".

Sentencia de 17 noviembre 1971. Sala 5: R. 4629: "sería preciso que la finalidad contraria a derecho se hubiere producido...".

Sentencia de 24 marzo 1972. Sala 5." R. 1372: «... faltan los elementos probatorios para que resulte viable la tesis de los apelantes, cuya representación, al propugnarla, 
Es importante subrayar la vinculación de la prueba a la existencia de hechos, sin que basten posturas de parte, que se sustancian en juicios de valor y suposiciones, como la práctica nos muestra tantas veces.

La dificultad efectiva reside, como es lógico, en articular una prueba eficaz, no digamos ya plena, por cuanto la sustancia de la desviación de poder, en sí, es difícilmente evidenciable. Ciertamente que lo que se pretende es llevar al convencimiento del Tribunal la existencia de la infracción, y aunque éste, muchas veces, juzga de modo directo de las actuaciones (26), en el terreno pragmático es necesario hacer tangible, visualizar, una estructura psicológica desviada teleológicamente, que ha precedido a un acto de corrección externa, lo cual, obviamente, es el tendón de Aquiles de la viabilidad de la acción. El éxito de la desviación de poder es un problema de técnica probatoria. En los casos en que se ha

descansa en juicios personales y meras suposiciones, carentes de eficacia y valor respecto de la deviación de poder».

Sentencia de 11 diciembre 1972. Sala 4." R. 5270: "siendo lo esencial para llegar a la apreciación de tal vicio en el acto que se impugne el que se demuestre una serie de hechos que lleven a estimar que la decisión administrativa se ha producido con una finalidad contraria...».

Sentencia de 1 marzo 1973. Sala 5. R. 915: «no se acredita en el que se enjuicia que el acuerdo del Pleno de la Corporación municipal adolezca de tales imperfecciones...".

Sentencia de 31 marzo 1975. Sala 4." R. 2385: "mal puede atribuirse un fin torpe o extraño, de otra parte no acreditado ni palmario...».

Sentencia de 1 julio 1975. Sala 4." R. 3804: "para su estimación no basta con que se alegue este instituto moralizador de la actividad administrativa, sino que ha de probarse...».

Sentencia de 12 noviembre 1975. Sala 5. R. 9337: «sin que pruebe en forma alguna la desviación de poder...».

Sentencia de 22 enero 1976 . Sala 4." R. 568: «es a la parte que alega la desviación de poder a quien incumbe la prueba...».

Sentencia de 10 mayo 1976. Sala 4." R. 3301: «no basta con que se alegue tal infracción, sino que ha de relacionarse con los hechos que sirven de soporte a la resolución en que se dice ha incidido tal desviación de poder, probando fehacientemente su existencia y realidad...».

Sentencia de 26 abril 1977. Sala 4. ${ }^{\mathrm{a}}$ R. 2649: «extremos que no se acreditan en vía administrativa ni jurisdiccional...».

Sentencia de 3 mayo 1978. Sala 5. R. 1668: «no existe prueba ni indicio de la misma que tienda a indicar una finalidad ilícita de esa exigencia; la pretensión del apelante ha de ser desestimada...».

Sentencia de 31 octubre 1978. Sala 3." R. 3413: «ninguna prueba se ha aportado para demostrar que ha servido a un fin diferente al previsto por las normas...».

Sentencia de 15 diciembre 1978. Sala 4." R. 4611: "debiendo sumar a lo expuesto que esta misma jurisprudencia viene exigiendo una prueba de los hechos sobre los que haya de basarse la desviación...».

(26) «Aparece plenamente justificado que para la Jefatura de la Guardia Municipal de una población como San Baudilio se estime mérito preferente el haber prestado como suboficial servicios en el Benemérito Cuerpo de la Guardia Civil.» 
aceptado, se ha llegado a ello a través de una serie de indicios convergentes que puntean un animus claro y definido, "pues, si esto no fuera así, entonces recobra toda su potencialidad el principio de presunción de legalidad del acto administrativo» (Sentencia de 15 diciembre 1978).

3. UN SUPUESTO DE APELACIÓN ADMITIDA CONTRA

SENTENCIA ACEPTATORIA DE DESVIACIÓN DE PODER.

INVALIDEZ «VERSUS» CERTEZA DEL ACTO ADMINISTRATIVO

La Sentencia de 15 diciembre 1978 nos plantea un singular caso en relación a nuestro tema.

Una Corporación municipal desestimó recurso de reposición contra certificación expedida por el Secretario de la misma, expresiva de que los terrenos en los que se pretendía instalar una estación de servicio reunían la condición de estar comprendidos en un perímetro edificado al menos en el 20 por 100 de su extensión superficial y que, en consecuencia, y por aplicación del artículo 66, 2, de la Ley del Suelo de 12 de mayo de 1956, tales terrenos se calificaban como "suelo urbano».

La Sala de la Audiencia de Valladolid, en 15 de septiembre de 1976, anuló tal acuerdo por desviación de poder.

La Sala Cuarta del Tribunal Supremo, en Sentencia de 15 diciembre 1978 (R. 4611), actuando como Ponente el Excmo. señor don Angel Martín del Burgo y Machán, citada, revoca en apelación la anterior, confirmando los acuerdos municipales.

En la argumentación revocatoria se manejan los siguientes razonamientos:

1) La calificación del suelo, a efectos de instalación de Estaciones de Servicio de CAMPSA, es un problema de hecho, que ha de resolverse a la luz de la prueba practicada.

2) Toda certificación municipal incursa en error, en cuanto se califique de suelo urbano al que no lo es, debe ser recurrida en reposición y, después, en vía contencioso-administrativa, ya que, de lo contrario, habría que respetar el acto firme y consentido (27).

(27) Sentencias de 19 enero 1963 (R. 55), de 21 febrero 1966 (R. 862), de 3 marzo 1966 (R. 1068), 29 de septiembre 1969 (R. 4049), de 9 febrero y de 2 noviembre 1971 (R. 692 y 4796), de 12 mayo 1972 (R. 2388) (Considerando primero, Sentencia de 15 diciembre 1978). 
El primer problema que se plantea y resuelve en sentido afirmativo es el de la calificación que puede recibir un certificado expedido por un Secretario de Administración local, ante una posible impugnación, en orden a si ha de entenderse como acto administrativo.

La Sentencia parte (Considerando $4 .^{\circ}$ ) de que «el acuerdo recurrido, que es el dictado por el Alcalde de B., el 24 de septiembre de $1974 \ldots$, contiene las determinaciones necesarias para configurarlo como verdadero acto administrativo, aun en su consideración más rigurosa y estricta». Subraya la propia Sentencia la gran atención seguida en su procedimiento para «alejar toda sospecha de parcialidad» (Considerando $5^{\circ}$ ).

No se considera posible la existencia de desviación de poder en la actuación de la Alcaldía, que se ha «limitado a ordenar la expedición de un certificado, por el Secretario de la Corporación, reducido a recoger en él el hecho de la inexistencia en esa población de Plan General o Parcial, así como lo informado por el Arquitecto municipal sobre determinado extremo" (Considerando $6 .^{\circ}$ ).

Tras una llamada a la doctrina tradicional sobre el concepto restrictivo de desviación de poder y el rigor de la prueba, se reduce la cuestión al informe del Arquitecto de la Corporación, su actuación, «sin duda, la más polémica, la que ha despertado mayores suspicacias, pues, además, es el contenido de su dictamen el que viene a plantear la situación conflictiva entre los implicados en que se establezca o no se establezca una nueva Estación de Servicio de carburantes en el sitio de autos».

El dictamen del técnico es, realmente, el contenido sustancial del acto administrativo, ya que viene a establecer la calificación de los terrenos. Otra cosa sería una visión parcial y formalista (28).

Contra el dictamen se alegaron tres argumentos básicos: a) La falta de atribuciones del perito Arquitecto para formular juicios de carácter jurídico; b) "la colusión de este facultativo con los intereses de la empresa solicitante del certificado en cuestión, al

(28) Considerando décimo: «lo afirmado en el precedente considerando lo está para contrarrestar la visión exclusivamente formalista que se derivaría de la reducción del acto complejo de que se trata (en el que se integra la orden de expedición y la aprobación o visto bueno del Alcalde, la certificación del Secretario y el dictamen del Arquitecto) a solo los actos procedentes de la primera autoridad municipal, ya que ello supondría una concepción parcial y mutilada del conjunto del acto administrativo, contraria, por tanto, a la realidad de las cosas, inmunizando a ese conjunto de las posibilidades revisoras de la jurisdicción sólo porque en uno o algunos de los fac. tores subjetivos intervinientes no se presenten síntomas de actuación viciosa». 
haberla servido particularmente confeccionando el proyecto de la urbanización, junto a la que se pretende instalar la Estación de Servicio litigiosa»; c) "la desviación de poder en que, por esta circunstancia, este técnico ha incurrido en esta ocasión».

Los tres argumentos son estudiados por la Sentencia.

La presunta incompetencia del Arquitecto para tratar sobre temas urbanísticos es rechazada con una invocación al carácter interdisciplinar del Urbanismo y la necesidad de unos principios unitarios, para las distintas parcelas científicas, en unas expresiones realmente insólitas en nuestras resoluciones judiciales, acuciadas, muchas de ellas, por el alud de la masificación (29).

La actitud del Arquitecto es calificada con una tipificación distinta a la desviación de poder: la incompatibilidad, "porque en un mismo asunto no se deben simultanear cometidos, cuando con ellos se compromete la posición de objetividad e imparcialidad necesaria e imprescindible para el normal ejercicio de la función pública» (Considerando 14).

Tras una referencia al Derecho aplicable a las incompatibilidades para los funcionarios estatales (art. 82 del texto articulado de Funcionarios Civiles del Estado, aprobado por Decreto de $7 \mathrm{fe}$ brero 1964, aplicable a los funcionarios locales por la técnica del reenvío), se llega a la diferenciación doctrinal de incompatibilidad e incapacidad, vinculando la primera con la validez del acto, y dejando aparte las sanciones a que haya lugar en régimen disciplinario, para desligar-en el caso-los planos de la validez y de la eficacia, por cuanto, se afirma, «al decir que el acto del funcionario incompatible es válido (en nuestro caso, el informe del tan repetido Arquitecto) no se prejuzga en absoluto la eficacia, por la sencilla razón de que en materia de dictámenes, su problemática no se mueve en el plano de la validez o invalidez, sino en el de la

(29) Considerando decimotercero: «a mayor abundamiento, el urbanismo es un campo interdisciplinar, en cuanto su comprensión no puede obtenerse a través de una sola ciencia, sino de varias, puesto que sólo a través de la colaboración de todas ellas podrán obtenerse soluciones satisfactorias; pero no solo esto, que no viene a ser más que un reflejo de lo que demanda la moderna filosofía de la ciencia, resueltamente favorable al establecimiento de unos principios unitarios, comunes a las distintas parcelas científicas, y contrario, por tanto, al cantonalismo y a la "barbarie" del especialismo atomizador; no sólo esto, repetimos, sino que es en el campo de la arquitectura, y como consecuencia de la vinculación de ésta al urbanismo, donde más se acusa esa necesidad de salirse de los conocimientos sólo pertenecientes a la especialidad de su técnica, siendo por ello por lo que en las Escuelas de Arquitectura en la actualidad existen Cátedras y Cursos de Derecho Urbanístico». 
verdad o la falsedad, en el de la certeza o el error» (Considerando 18).

Con ello llegamos ya a la principal aportación de esta Sentencia: la necesidad de enfocar el problema de fondo con la proverbial e inapreciable actitud del Magistrado, la objetividad y la ponderación, yendo más allá de las líneas exteriores de los acontecimientos. La materia de la desviación de poder parece conllevar un cierto parti pris, para todos los que intervienen en su enjuiciamiento. La desviación, cuando se acepta, en una resolución, es aceptada alborozadamente por la doctrina más diversa, en cuanto en ello se ve el triunfo de una apertura a formas de control más libre y esencial, como se viene solicitando por los autores desde hace lustros.

Sin negar que toda anulación de un acto opuesto a ordenamiento jurídico supone un beneficio para la Administración y para el propio interés público, que se ve restablecido en un punto tan importante como es la seguridad jurídica, entendemos que, en esta materia, como en tantas otras expuestas a la pasión humana, en todas sus explicables formas, dentro de la dignidad y del decoro, la importancia de una actitud libre y basada en la realidad de los hechos debe ser también subrayada y glosada.

El Magistrado cumple esta difícil misión de ponderar los extremos y corre con el difícil papel de decidir la cuestión según los hechos. La actitud de ir a la realidad de las cosas y de los hombres con una mentalidad esencial, sustancial, creemos que es volver a la raíz de la función judicial que permite, sin duda, cualquier progreso y evolución que el mundo circundante, en su coseidad, su objetividad y su peso específico, puede exigir y sugerir.

En esta Sentencia, a pesar de que «las dudas que puedan despertar la lamentable situación creada por este técnico, si no afectan a la validez del acto, conmueven la base de credibilidad de su imparcialidad, y, a consecuencia, la credibilidad en su obra y en su actuación» (Considerando 17), la Sala conoce de la cuestión de fondo con la plenitud de efectos del recurso de apelación y desprendiéndose de la carga psicológica que la misma entrañaba.

Tras afirmar que «... tales dudas no impiden llegar a una conclusión coincidente con la sentada en el informe cuestionadon (Considerando 18), se relacionan una serie de hechos, para concluir que "este conjunto de pruebas evidencia, pues, que el informe o dictamen tal referido es sospechoso, por la posición de su autor, pero no falso ni erróneo...». 
Vista la confirmación de la naturaleza de los terrenos, que controla y define de modo autónomo, la Sentencia llega a la revocación de la inferior, donde se aceptó la desviación, añadiendo obitur dictum un argumento sobre la conveniencia de conceder una interpretación extensiva al intervencionismo administrativo (30).

\section{CONCLUSIONES}

1. ${ }^{a} \quad$ El estudio de la desviación de poder, en la Administración local, en su más estricta actualidad, nos demuestra que la institución no ha seguido la línea de decadencia creciente y progresiva que podía esperarse de su evolución, en la cota de los años setenta.

La desviación de poder sigue siendo un motivo de anulación con plena vigencia, aunque siempre es aceptada con extremada parsimonia y espaciadamente, por nuestro Tribunal Supremo.

$\mathrm{Su}$ alegación-con el conocido efecto de abrir la apelación al Tribunal Supremo-es un fenómeno de constante presencia.

2. ${ }^{a}$ La desviación de poder tiene especial interés para los funcionarios de la Administración local y, entre ellos, Secretarios e Interventores de Fondos, por su participación en el proceso de producción de los actos administrativos.

La desviación de poder se halla esencialmente imbricada con el interés general, de conformidad con su definición y con la limitación jurisprudencial que la casuística ha perfilado.

La desviación de poder es aceptada en aquellos casos en los que el alejamiento del interés público es flagrante, por lo cual la evitación de tal situación límite ostenta un innegable fondo deontológico para los funcionarios, dentro de sus posibilidades.

3. ${ }^{a}$ La subsidiariedad y carácter interno de la desviación la sitúan en el plano de un título de anulación ágil y elástico, sólo

(30) «La Sentencia recurrida ha de ser revocada, no sólo por mantener una argumentación totalmente contraria a la que aquí se sostiene, sino también por la poca fortuna al realizar el enorme esfuerzo desplegado en su fundamentación para llegar a una consecuencia que no sólo no es conforme a derecho, sino que implica una restricción no justificada al ejercicio de la actividad industrial y comercial...». «... una prueba evidente de lo que acaba de exponerse es el hecho de que en una actividad tan reglamentada como es la farmacéutica... no ha sido bbice para que la jurisprudencia, en todos los casos dudosos, se haya inclinado por las interpretaciones muy flexibles, fomentando en lo posible la apertura de nuevas farmacias..., doctrina que tiene aún más sentido en el ámbito de la actividad de que se trata en el proceso que nos ocupa, puesto que el privilegio de las estaciones de servicio ya montadas ni siquiera ha requerido, como en el caso de las farmacias, la posesión de un título académico superior, a más del capital necesario, sino sólo esto último, más la oportunidad de llegar a tiempo para ocupar un lugar más o menos conveniente». 
actuable cuando el acto es formalmente correcto; pero no en su esencialidad intencional, siendo, por ello, una garantía de la justicia material y de la corrección de la propia Administración.

El trasfondo, forzosamente generalista, de la figura, explica su vitalidad y continuidad, aun limitada a las estrechas dimensiones observables en nuestro panorama jurisprudencial.

Esta vigencia larvada nos parece que será una característica de su futuro. Existen factores sociológicos e históricos que abonan una previsible pervivencia de la desviación de poder, tantas veces imputada, como puro nominalismo, a la Administración y tan pocas veces aceptada en el plano real de las Sentencias. Nos referimos a las exigencias sociales de objetivismo y adaptación a los estándares de justicia material, frente al Derecho administrativo, agudizadas por el aumento de la tecnología, la alienación y el incremento de los centros de poder marginales a la propia Administración, pero incidentes, en la misma, en su axiología y en sus técnicas.

Sin duda que este proceso de apertura y participación del Derecho administrativo, que viene pidiendo la opinión popular y la doctrina científica, ha de ser una coyuntura favorable para la floración de una causa de anulabilidad tan específica como es la desviación de poder, dotada de una fuerza expansiva notable y que puede ser una posible válvula de seguridad para muchas tensiones que desembocarán ante los Tribunales contencioso-administrativos.

La desviación de poder es un destello, intermitente, pero esperanzador, de esta luminosa aporía eterna, la lucha por el Derecho, tan cara a los juristas de todos los tiempos. 